\title{
Bladder preservation with brachytherapy compared to cystectomy for TI-T3 muscle-invasive bladder cancer: a systematic review
}

\author{
Manouk K. Bos, Rafael Ordoñez Marmolejo, MD, Coen R.N. Rasch, MD, PhD, Bradley R. Pieters, MD, PhD \\ Department of Radiation Oncology, Academic Medical Center, University of Amsterdam, Amsterdam, The Netherlands
}

\begin{abstract}
Purpose: Radical cystectomy currently is the treatment of choice in muscle-invasive bladder cancer. However, cystectomy is associated with considerable morbidity. Bladder sparing treatment consists of transurethral resection of the tumor (with or without partial cystectomy), external beam radiotherapy, and brachytherapy. The purpose of this study is to compare bladder preservation with brachytherapy to cystectomy by a systematic review.

Material and methods: A systematic review was conducted using PubMed electronic database. Article selection was done independently by two authors. Data were extracted on cause-specific survival and overall survival at 2, 5, and 10 years. Comparison of the two treatment modalities was done by a Weibull survival analysis with metaregression analysis and estimation of Hazard Ratio's (HR's) with 95\% confidence intervals (CI).

Results: Large differences in tumor staging and tumor grading were found between cystectomy and bladder sparing series. The adjusted HR's for cause-specific survival and overall survival were 1.27 (95\% CI: 1.15-1.40) and 0.85 (95\% CI: 0.84-0.87), respectively for bladder sparing relative to radical cystectomy.

Conclusions: Robustness of the analysis is hampered by the retrospective character of the study and differences in patient characteristics. For selected cases, bladder sparing by brachytherapy leads to at least similar overall survival compared to radical cystectomy for muscle invasive bladder cancer.
\end{abstract}

Key words: bladder neoplasms, brachytherapy, cystectomy, meta-analysis, systematic review.

\section{Purpose}

Urothelial carcinoma of the bladder, comprising $90 \%$ of all primary bladder tumors, is the fourth most prevalent type of cancer in men. The number of estimated new cases and estimated deaths for 2013 are 72,570 and 15,210, respectively [1]. Currently, the treatment of choice in muscle invasive bladder cancer (MIBC) is radical cystectomy with pelvic lymphadenectomy. Stein et al. reported a 5 and 10 year overall survival of $60 \%$ and $43 \%$, respectively [2]. Comparable results were reported by Park et al. [3] and Ghoneim et al. [4] Park et al. reported a 5 year survival of $61 \%$ [3]. Overall survival rates were stratified by lymph node negative and lymph node positive patients by Ghoneim et al., who reported a five and ten year overall survival rate of $62 \%, 56 \%, 27 \%$, and $23 \%$, respectively [4]. Important prognostic factors for survival are extravesical tumor extension and lymph node status [2-4]. Radical cystectomy comes with considerable morbidity such as erectile dysfunction, urinary leakage, urinary tract infection, and most important of all lost of normal bladder function [5].
Bladder preserving therapy may then offer an alternative to radical cystectomy with a possible reduction of side effects. A treatment modality for organ preservation is partial cystectomy preferably preceded by cisplatin-based neoadjuvant chemotherapy [6]. Compared to radical cystectomy, partial cystectomy results in a comparable cause-specific survival in a highly selected group of patients. However, $38 \%$ of the patients treated with partial cystectomy experienced intravesical tumor recurrence [7]. In a review of the literature, Kuczyk et al. reported a local recurrence after partial cystectomy varying between $38 \%$ and $78 \%$ after partial cystectomy, based on available literature [8]. Herr et al. provided data on local recurrence for patients with muscle invasive bladder cancer treated with only transurethral resection. Bladder recurrence with muscle invasive tumors was 34\% [9]. In a highly selected group of 13 patients, partial cystectomy after neoadjuvant chemotherapy resulted in $38 \%$ intravesical recurrences, of which $23 \%$ were invasive [10].

To increase local tumor control, some groups advocate combining organ-preserving surgery of the bladder 
with external beam radiotherapy and brachytherapy (EB-BRACH) [11]. This multi-modality approach can be considered in patients with a solitary, stage pT1-pT3, $\leq 5 \mathrm{~cm}$ bladder cancer [12]. Recent studies have shown that this multimodality strategy has good results in a selected group of patients [12-14]. An advantage of this conservative approach is the preservation of bladder function. Another conservative approach for muscle-invasive bladder cancer is chemoradiation. In a recent randomized study, fluorouracil-mitomycin C chemoradiation resulted in significantly better loco-regional disease-free and overall survival compared to radiotherapy alone [15]. In contrast to brachytherapy, also large T2-4 and multifocal tumors are candidate for chemoradiation. Compared to brachytherapy, external beam radiotherapy (EBRT) has the potential risk of increased toxicity, because of a larger radiation volume, to particularly the small bowel.

In this study, a systematic review with meta-regression analysis is performed to investigate if conservative treatment with brachytherapy will result in similar survival outcome as radical cystectomy.

\section{Material and methods}

A systematic review was conducted of the literature published on radical cystectomy and bladder brachytherapy for muscle invasive bladder cancer between January 1981 and December 2012 available in the PubMed database. Two different searches were done to identify articles on radical cystectomy and brachytherapy. Terms used for the search were bladder neoplasms in combination with survival, survival analysis, treatment outcome, treatment efficacy, and treatment effectiveness. These terms were combined with cystectomy or brachytherapy. Also synonyms of the terms were used (Table 1).
The search for articles on radical cystectomy identified 2325 articles. Articles were further selected by reading the title and abstract, after which 537 articles remained. We excluded reviews, case reports, articles with a population of 30 or less patients, median follow-up 24 months or less, node positive disease, other stages than T1-T3, uncommon histology (small cell carcinoma, rhabdomyosarcoma i.e.) and salvage cystectomy. Only articles written in English were included. Because brachytherapy studies did not use neoadjuvant chemotherapy, which is a known predictive factor for treatment outcome, we excluded studies with patients who received neoadjuvant chemotherapy. Data stratified by biological markers were not used. From different studies and based on the same patient cohort, the article with the largest cohort, most recent publication date or most thorough data analysis was included.

The search for articles on brachytherapy identified 57 articles, which were further selected by reading the title and abstract. Thirty-two articles remained. Two articles were excluded, because the patient population was $\leq 30$. Articles derived from patients who were included in the large multi-institutional series of Koning et al. [12] were excluded to avoid analysis of double data. In total, 7 studies were included.

Two authors independently did article selection and data extraction ( $\mathrm{MB}$ and $\mathrm{RO}$ ). The following data were extracted from the articles: year of publication, number of patients, type of study (randomized controlled trial, cohort and case-control), median follow-up time, mean or median age, total number of patients, number of patients in each tumor stage (T1-T3), differentiation grade, tumor size, multifocality (yes vs. no), adjuvant chemotherapy (yes vs. no), overall survival (OS) at 2, 5, and 10 years with standard errors and cause-specific survival (CSS) at 2, 5, and, 10 years with standard errors. Missing standard

Table 1. Keyword search terms

\begin{tabular}{|c|c|c|}
\hline Search & Search Terms Cystectomy & Hits \\
\hline 1 & Cystectomy [Mesh] OR Cystectomy [Tiab] OR Cystectomies [Tiab] & 10631 \\
\hline 2 & $\begin{array}{l}\text { Urinary Bladder Neoplasms”[Mesh] OR Bladder Neoplasm[Tiab] OR Bladder Tumor*[Tiab] } \\
\text { OR Bladder Cancer*[Tiab] }\end{array}$ & 46397 \\
\hline 3 & $\begin{array}{l}\text { Survival[Mesh] OR Survival[Tiab] OR Survival Analysis[Mesh] OR Treatment Outcome[Mesh] } \\
\text { OR Treatment Outcome[Tiab] OR Treatment Efficacy[Tiab] OR Treatment Effectiveness[Tiab] }\end{array}$ & 1110945 \\
\hline 4 & \#1 AND \#2 AND \#3 & 2924 \\
\hline 5 & \#3 Limits: 1981/01/01 to 2012/12/01 and studies published in English & 2325 \\
\hline Search & Search Terms Brachytherapy & Hits \\
\hline 1 & Brachytherapy [Mesh] OR Brachytherapy [Tiab] & 17547 \\
\hline 2 & $\begin{array}{c}\text { Urinary Bladder Neoplasms”[Mesh] OR Bladder Neoplasm*[Tiab] OR Bladder Tumor*[Tiab] } \\
\text { OR Bladder Cancer*[Tiab] }\end{array}$ & 46397 \\
\hline 3 & $\begin{array}{l}\text { Survival[Mesh] OR Survival[Tiab] OR Survival Analysis[Mesh] OR Treatment Outcome[Mesh] } \\
\text { OR Treatment Outcome[Tiab] OR Treatment Efficacy[Tiab] OR Treatment Effectiveness[Tiab] }\end{array}$ & 1110945 \\
\hline 4 & \#1 AND \#2 AND \#3 & 69 \\
\hline 5 & \#3 Limits: 1981/01/01 to 2012/12/01 and studies published in English & 57 \\
\hline
\end{tabular}


errors for survival time were estimated using the number of patients at risk. The number of patients in each pathological tumor stage was used, if mentioned. When the pathological tumors stage was not mentioned, we used clinical tumor staging.

\section{Statistics}

The two treatment modalities were compared using overall survival and cause-specific survival. The Weibull survival analysis was used to analyze survival differences between the two groups. Differences between the groups were expressed as hazard ratio's (HR) with 95\% confidence interval $(95 \% \mathrm{CI})$. For analysis a fixed-effect model was applied. Studies, which presented only data stratified by tumor stage, were imported as separated studies into the database. A stepwise multivariate regression analysis was performed on the $\ln (-\ln$ (probability of survival)) as the dependent variable.

Type of treatment (cystectomy vs. EB-BRACH), percentage of patients with tumor stage $\geq$ Tis $\leq \mathrm{T} 2$, percentage of patients with grade 3 , median age (if not available the mean age was used), and adjuvant chemotherapy (yes vs. no) were the independent covariates entered into the model. Associations with a $p$-value $\leq 0.05$ (two-sided) were considered as significant. The analysis was performed using IBM SPSS Statistics Version 19.0 (PASW 19.0, Chicago, IL, USA).

\section{Results}

In total, 19 articles were used for this analysis; 7 articles on brachytherapy and 12 articles on radical cystectomy. All articles were retrospective cohort studies. The characteristics of the included articles are summarized in Table 2 and 3. Patient characteristics and 5 and 10-year survival rates are summarized in Table 4. Analysis was done on 2, 5 , and 10 year overall and cause-specific survival.

\section{Overall survival}

A significant lower OS was found for cystectomy than for brachytherapy in both univariate- and multivariate analysis. The HR of overall survival was 0.79 (95\% CI: 0.77-0.81) for brachytherapy relative to cystectomy in univariate analysis. This yields a 5 and 10 years survival of

Table 2. Summary of selected articles

\begin{tabular}{|c|c|c|c|c|}
\hline First author & Year of publication & $\begin{array}{l}\text { Number } \\
\text { of patients }\end{array}$ & $\begin{array}{l}\text { Median follow-up } \\
\text { (months) }\end{array}$ & $\begin{array}{c}\text { Adjuvant chemotherapy } \\
\text { used? }\end{array}$ \\
\hline \multicolumn{5}{|l|}{ Cystectomy } \\
\hline Cheng L [16] & 2000 & 148 & 60 & Yes \\
\hline Nieuwenhuijzen JA [17] & 2005 & 77 & 30 & No \\
\hline Pagano F [40] & 1991 & 64 & 41 & No \\
\hline Quek ML [41] & 2003 & 86 & NM & No \\
\hline Madersbacher S [42] & 2003 & 320 & 31 & No \\
\hline Jeon SH [43] & 2005 & 41 & 77 & No \\
\hline Dhar NB [44] & 2008 & 239 & 30 & NM \\
\hline Stein JP [45] & 2009 & 41 & NM & Yes \\
\hline Shariat SF [46] & 2009 & 398 & 57 & No \\
\hline May M [47] & 2011 & 78 & 47 & No \\
\hline Hautmann RE [48] & 2012 & 560 & 38 & No \\
\hline Neuzillet Y [49] & 2012 & 75 & 58 & Yes \\
\hline \multicolumn{5}{|l|}{ Brachytherapy } \\
\hline Koning CCE [12] & 2012 & 1040 & 48 & No \\
\hline Rozan R [13] & 1992 & 205 & 51 & No \\
\hline Pernot M [14] & 1996 & 85 & 84 & No \\
\hline De Crevoisier R [19] & 2004 & 58 & 52 & No \\
\hline Williams GB [50] & 1981 & 89 & NM & No \\
\hline Mazeron J [51] & 1988 & 85 & NM & No \\
\hline Van der Werf-Messing BHP [52] & 1989 & 90 & NM & No \\
\hline
\end{tabular}


Table 3. Surgical and radiation characteristcs for the selected brachytherapy articles

\begin{tabular}{|c|c|c|c|c|c|c|}
\hline First author & $\begin{array}{l}\text { Extent of } \\
\text { resection at time } \\
\text { of implantation }\end{array}$ & $\begin{array}{l}\text { Target } \\
\text { volume } \\
\text { for EBRT }\end{array}$ & Dose & EBRT technique & $\begin{array}{c}\text { Brachytherapy } \\
\text { isotope and } \\
\text { modality }\end{array}$ & Sequencing \\
\hline Koning CCE [12] & $\begin{array}{l}\text { No resection in } \\
76 \% \text { and } P C \text { in } \\
24 \%\end{array}$ & NM & $\begin{array}{c}\text { EBRT: } 10-55 \text { Gy } \\
\text { Brachytherapy: } \\
\text { 25-60 Gy }\end{array}$ & NM & LDR, PDR, HDR & $\begin{array}{c}\text { Brachytherapy } \\
\text { after EBRT }\end{array}$ \\
\hline Rozan R [13] & $\begin{array}{c}P C \\
\text { Homo- and } \\
\text { bilateral LND }\end{array}$ & $\begin{array}{c}\text { Bladder: } \\
21.5 \% \\
\text { Pelvis: } 78.5 \%\end{array}$ & $\begin{array}{c}\text { EBRT: mean } 11 \text { Gy } \\
\text { Brachytherapy: } \\
\text { 30-50 Gy }\end{array}$ & $\begin{array}{l}{ }^{60} \text { Co or linear } \\
\text { accelerator }(5.5 \\
\text { MV-25MV) }\end{array}$ & $\begin{array}{l}192 / r \\
\text { LDR }\end{array}$ & $\begin{array}{c}\text { Brachytherapy } \\
\text { after EBRT }\end{array}$ \\
\hline Pernot M [14] & $\begin{array}{l}\text { No resection } \\
\text { and PC } \\
\text { No LND and } \\
\text { homo- and } \\
\text { bilateral LND }\end{array}$ & NM & $\begin{array}{c}\text { EBRT: } 3 \text { x } 3.5 \text { Gy } \\
\text { Brachytherapy: } \\
\text { 30-50 Gy }\end{array}$ & APPA, $25 \mathrm{MV}$ & $\begin{array}{l}{ }^{192} \text { Ir } \\
\text { LDR }\end{array}$ & $\begin{array}{l}\text { Brachytherapy } \\
\text { after EBRT } \\
\text { Postoperative } \\
\text { EBRT for thick } \\
\text { tumors }\end{array}$ \\
\hline $\begin{array}{l}\text { De Crevoisier } \\
\text { R [19] }\end{array}$ & $\begin{array}{c}P C \\
\text { Homo- and } \\
\text { bilateral LND }\end{array}$ & Pelvis & $\begin{array}{c}\text { EBRT: 5.5-17 Gy } \\
\text { Brachytherapy: } \\
\text { 50-70 Gy }\end{array}$ & APPA & $\begin{array}{l}192 / r \\
\text { LDR }\end{array}$ & $\begin{array}{c}\text { Brachytherapy } \\
\text { after EBRT }\end{array}$ \\
\hline Williams GB [50] & No resection & $\begin{array}{c}\text { No EBRT } \\
\text { performed }\end{array}$ & NM & $\begin{array}{c}\text { No ERBT } \\
\text { performed }\end{array}$ & $\begin{array}{c}{ }^{198} \mathrm{Au} \text { and }{ }^{182} \mathrm{Ta} \\
\text { LDR }\end{array}$ & $\begin{array}{c}\text { Only } \\
\text { brachytherapy }\end{array}$ \\
\hline Mazeron JJ [51] & $\begin{array}{c}\text { PC } \\
\text { Homo- and } \\
\text { bilateral LND }\end{array}$ & Pelvis & $\begin{array}{l}\text { EBRT: } 1 \text { × } 8.5 \text { Gy } \\
\text { If N+: } 30 \text { Gy post } \\
\text { brachytherapy } \\
\text { Brachytherapy: } \\
\text { 30-60 Gy }\end{array}$ & APPA, $25 \mathrm{MV}$ & $\begin{array}{l}{ }^{192} \text { Ir } \\
\text { LDR }\end{array}$ & $\begin{array}{c}\text { Brachytherapy } \\
\text { after EBRT } \\
30 \text { Gy EBRT post } \\
\text { brachytherapy } \\
\text { if } \mathrm{N}_{+}\end{array}$ \\
\hline $\begin{array}{l}\text { Van der } \\
\text { Werf-Messing } \\
\text { BHP [52] }\end{array}$ & No resection & Pelvis & $\begin{array}{c}\text { ERBT: } 20 \times 2 \text { Gy } \\
\text { Brachytherapy } \\
25 \text { Gy }\end{array}$ & APPA & $\begin{array}{l}{ }^{137} \mathrm{Cs} \\
\mathrm{LDR}\end{array}$ & $\begin{array}{c}\text { Brachytherapy } \\
\text { after EBRT }\end{array}$ \\
\hline
\end{tabular}

EBRT - external beam radiotherapy, APPA - anterior-posterior opposing portals, MV - megavolt, PC - partial cystectomy, LND - lymph node dissection, N+ - pathologic lymph nodes, $L D R$ - low-dose rate, $P D R$ - pulsed-dose rate, HDR - high-dose rate, NM-not mentioned

$62 \%$ and $45 \%$ after brachytherapy, and $54 \%$ and $36 \%$ after cystectomy. In the multivariate analysis, the HR was 0.85 (95\% CI: 0.84-0.87). This yields a 5 and 10 years survival of $62 \%$ and $45 \%$ after brachytherapy, and $57 \%$ and $40 \%$ after cystectomy. Covariates that remained in the multivariate analysis were type of treatment, percentage of patients with tumor stage $\geq$ Tis $\leq \mathrm{T} 2$, median age and adjuvant chemotherapy. The estimated survival curves adjusted for confounders for OS are illustrated in Figure 1.

\section{Cause-specific survival}

No significant difference was found in CSS between brachytherapy and radical cystectomy with univariate analysis ( $p$-value 0.713 ). With adjustment for confounders, a significant difference between both treatments was seen. The HR was 1.27 (95\% CI: 1.15-1.40) for brachytherapy relative to radical cystectomy. This yields a 5 and 10 years survival of $71 \%$ and $57 \%$ after brachytherapy, and $76 \%$ and $64 \%$ after cystectomy. Covariates that remained in the multivariate analysis were type of treatment, percentage of patients with tumor stage $\geq \mathrm{Tis} \leq \mathrm{T} 2$ and median age. The estimated survival curves adjusted for confounders for cause-specific survival are illustrated in Figure 2.

\section{Discussion}

The purpose of this systematic review is to compare results of radical cystectomy with bladder preservation by brachytherapy combined with EBRT and in most cases, partial cystectomy. This review has some limitations considering the non-randomized character of this analysis. Patient characteristics varied among both treatment groups. Comparison of brachytherapy series to cystectomy series can be hampered by differences in tumor staging. The cystectomy cohort consisted of a larger amount of patients with tumor stage T3. Furthermore, the brachytherapy group included only patients with tumors less than $5 \mathrm{~cm}$. It is likely that patients in the cystectomy group had tumors with sizes exceeding $5 \mathrm{~cm}$, but this remains unknown for most included studies since tumor size is not a criterion for cystectomy treatment and therefore often not reported. Tumor diameter and tumor stage were not significantly related to local control, as reported for both brachytherapy [12] and cystectomy [16]. However, Cheng et al. did find that tumor diameter and tumor stage are significantly associated with CSS with HRs of 1.2 (95\% CI: 1.1-1.4), and 1.4 (95\% CI: 1.1-1.9), respectively [16]. Furthermore, Nieuwenhuijzen et al. reported that tumor stage was significantly related to overall survival and disease-specific survival with HRs of 2.2 (95\% CI: 1.0-4.7) and 2.4 (95\% CI: 1.0-6.1) [17]. When bladder preservation is done, as it is the case for brachytherapy no pathological tumor staging information is obtained. The reported tumor staging is based on clinical ground after a cystoscopy, transurethral resection of tumor (TURT), bimanual palpation, and CT or MRI investigation. Clin- 


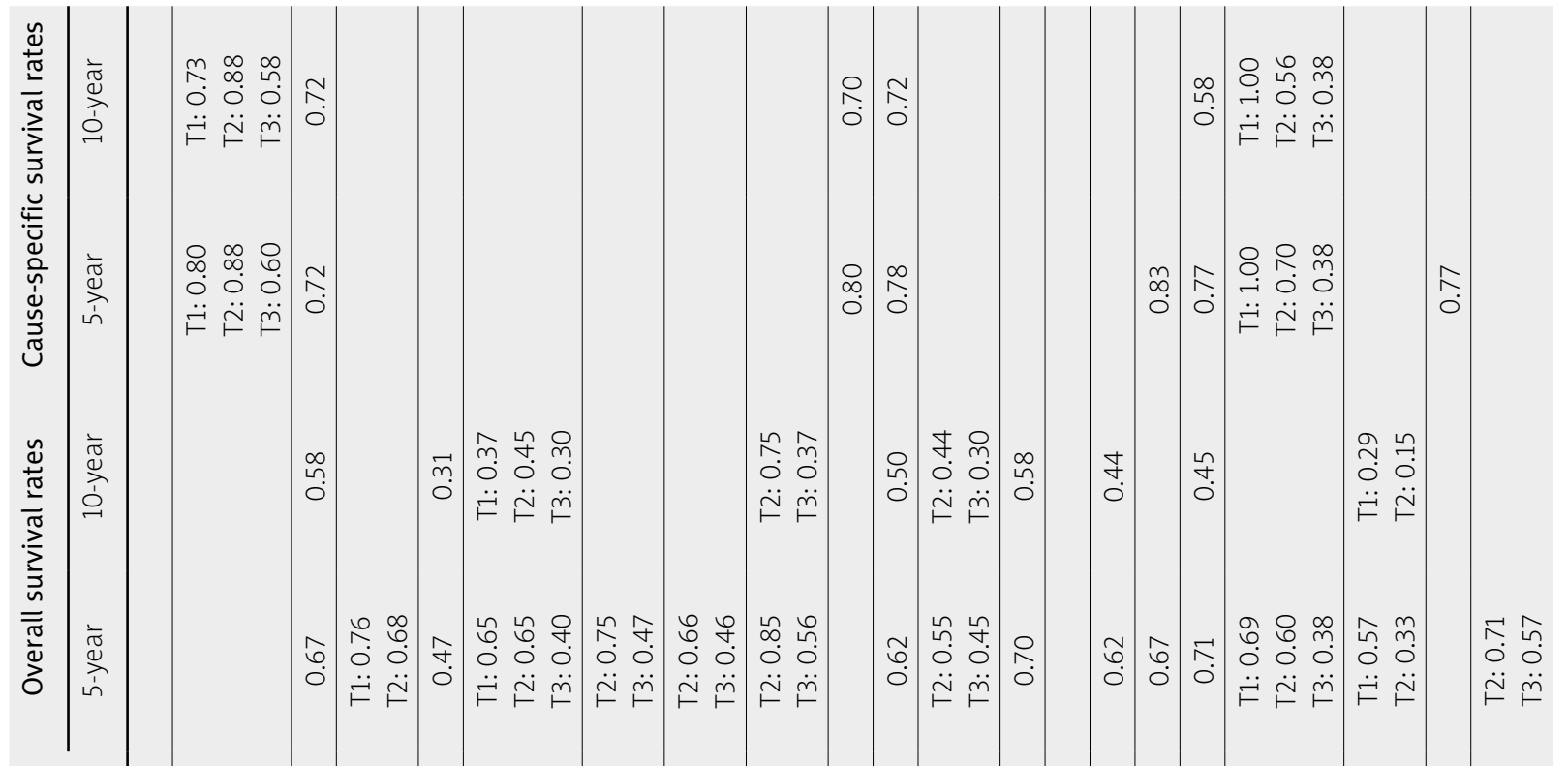

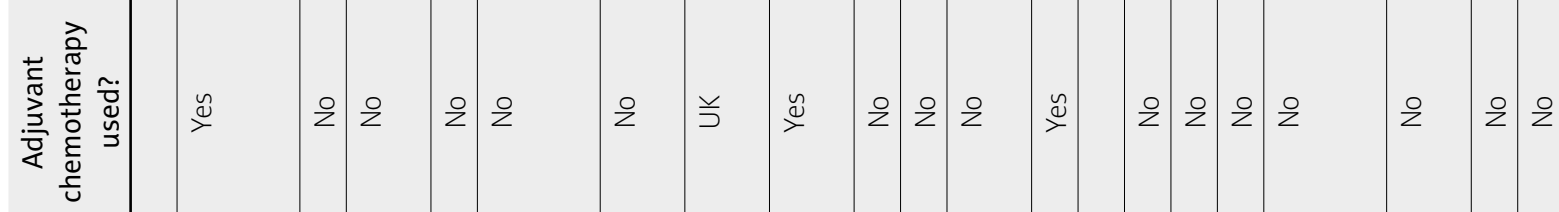

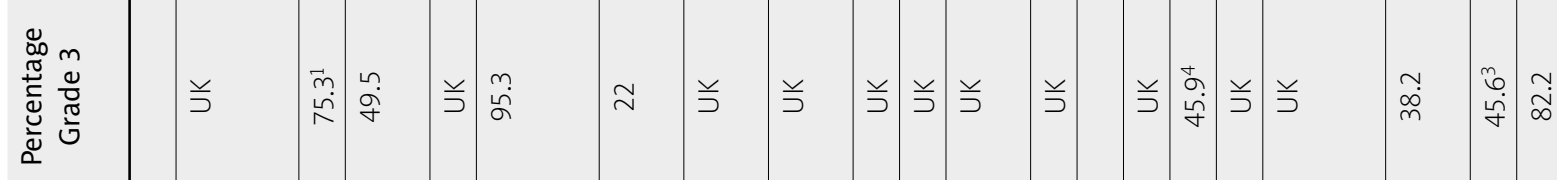

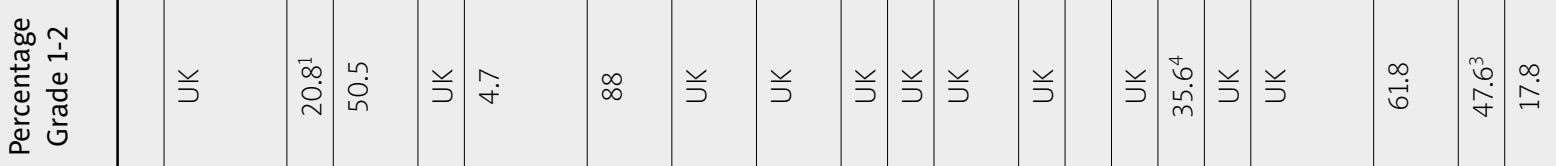

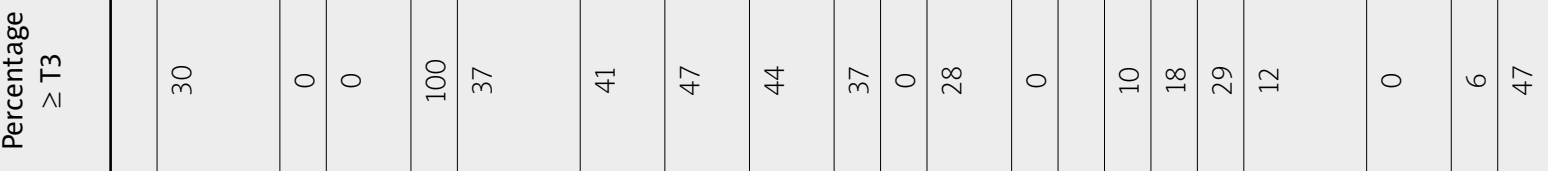
変

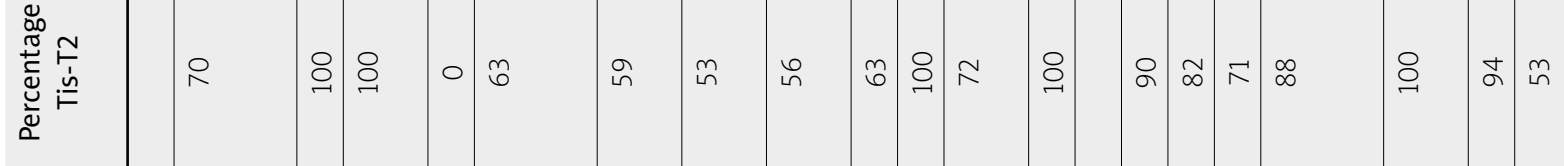

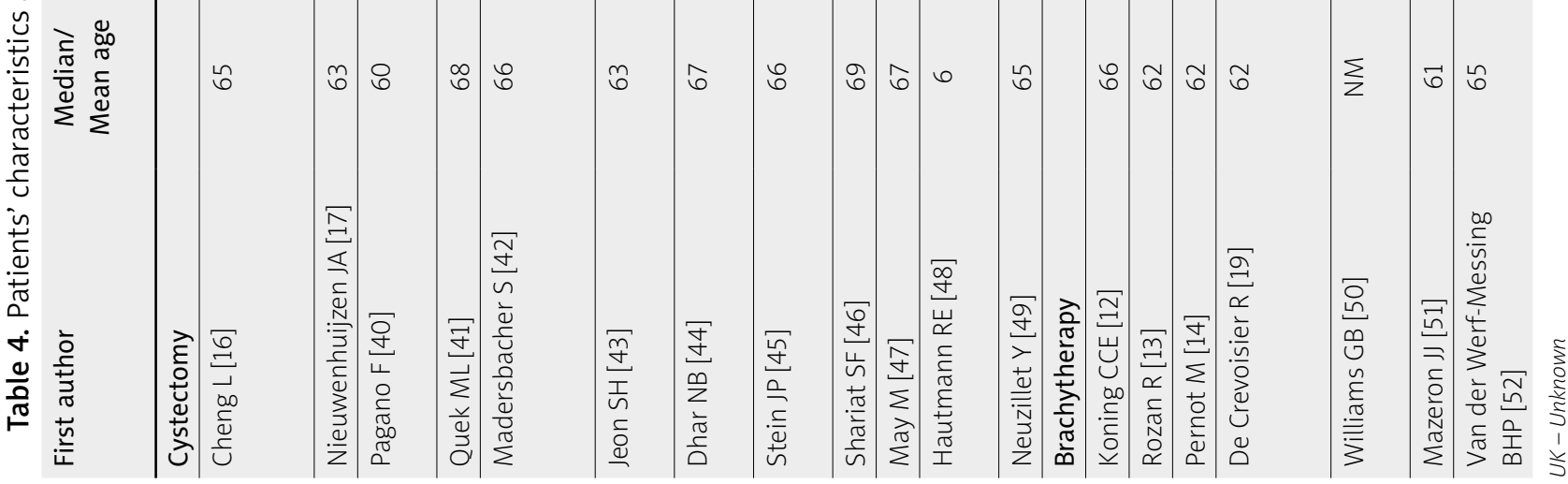




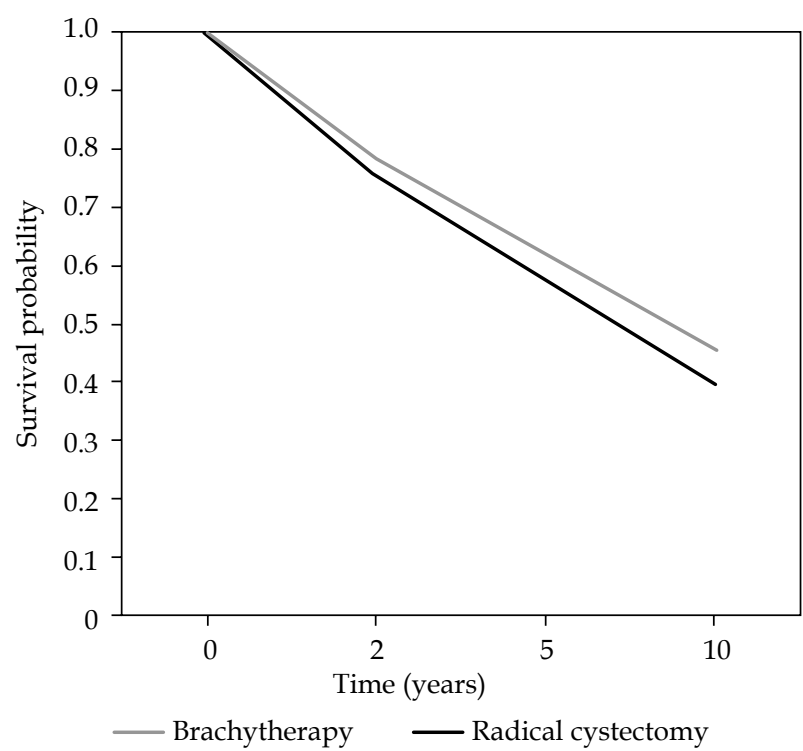

Fig. 1. Overall survival curves for brachytherapy and cystectomy, adjusted for confounders

ical staging often results in a different stage compared to pathological staging after a cystectomy. In about one third of the cases, clinical understaging is found for patients that have undergone cystectomy [18]. Only in the study of de Crevoisier et al. an attempt is done to correlate clinical with pathological staging [19]. They could do that, because al their patients received a partial cystectomy. The only discrepancy they saw was an upstaging for 3 clinical T2 cases to pathological T3. Considering the short period preoperative external beam dose (1-2 fractions) that was given, radiation downstaging was not expected. In our study cystectomy series are usually based on pathological staging and radiotherapy series on clinical staging. A discrepancy between clinical staging for brachytherapy and pathological staging for cystectomy is therefore plausible. This is a favorable bias for the cystectomy cohort, since clinical staging is more likely to understage the extent of the tumor [20]. Better survival outcome can be expected for the cystectomy cohort solely based on tumor stage selection bias.

Randomized data for comparison of these treatment modalities are lacking. Therefore, this study was necessarily limited to retrospective data. Local recurrence and disease-free survival had no endpoints in this analysis, because these data were unfortunately missing in most studies. Therefore, we had to exclude studies that only reported on local recurrence or disease-free survival. Another limitation of this systematic review is the exclusion of studies in which neoadjuvant chemotherapy was given. Neoadjuvant chemotherapy was exclusively given in cystectomy series and not in the brachytherapy series. From randomized studies and a systematic review, a 5-8\% improvement in overall survival can be expected with the addition of neoadjuvant cisplatin-containing chemotherapy [21-24]. To have a fair comparison between cystectomy and brachytherapy groups, cystectomy studies with neoadjuvant chemotherapy were excluded from this systematic review. However, given the advantage of

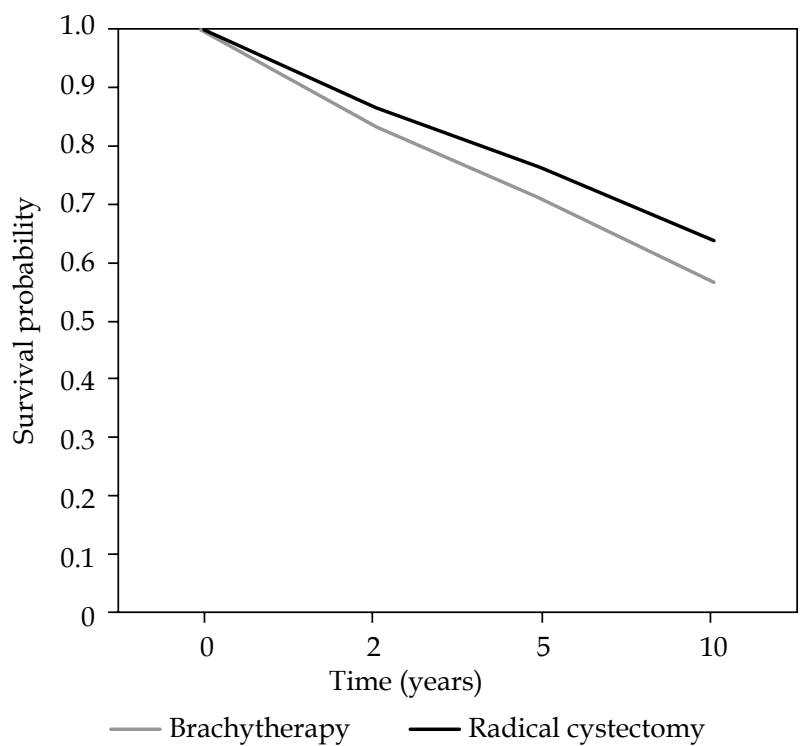

Fig. 2. Cause-specific survival curves for brachytherapy and cystectomy, adjusted for confounders

neoadjuvant chemotherapy on overall survival, it should always be considered and discussed with patients.

This review shows no significant difference in CSS in the univariate comparison between brachytherapy and cystectomy. After adjustment for possible confounders, the hazard ratio was 1.27 for brachytherapy relative to radical cystectomy. However, due to the retrospective character of this review, it cannot be excluded that one or several biases have influenced the result of the analysis as discussed previously. Therefore, the evidence for a difference in CSS between brachytherapy and cystectomy is not robust. In addition, the analysis on CSS miss data of the largest brachytherapy cohort of Koning et al. [12], which means that this analysis is based on a smaller brachytherapy treatment group than the analysis for OS. Analysis of OS results in better outcomes for the brachytherapy group compared to radical cystectomy. This suggests that patients in the cystectomy group might be more likely to die from other causes than from recurrent cancer compared to the brachytherapy group, and therefore it may appear that OS is better in the brachytherapy group. However, this is not very likely considering the fact that important data for brachytherapy are missing in the analysis of CSS. Moreover, grading was not included in the statistical models, because this information was often not reported in the studies. For the studies that have reported on grade, it seems that in the cystectomy series more patients had high-grade tumors than in brachytherapy series. On the other hand, the significance of grade is questionable for T2 and higher stage tumors $[25,26]$. From this systematic review, we cannot assume that one treatment modality is superior to the other. Notwithstanding, these limitations and this review indicates that the management of selected cases of muscle invasive bladder cancer with brachytherapy as bladder sparing treatment modalities does not negatively affect survival. One recent brachytherapy article that was published after this systematic review is of Aluwini et al. This cohort was not 
included in the Dutch cohort study of Koning et al. In the Aluwini study 192 patients with T2-T3b muscle-invasive bladder cancer and a median follow-up of 105.5 months are described. All patients underwent bladder conservative treatment with brachytherapy. The 5 and 10 year overall survival rates were $65 \%$ and $46 \%$, whereas the cancer-specific survival at 5 and 10 years was $75 \%$ and $67 \%$ [27]. These figures are in accordance to the figures of the included articles of this systematic review and would not alter the results.

The outcomes of this review are consistent with other studies, although data remain limited. Literature describes two studies that compared brachytherapy with radical cystectomy in a single institution experience $[17,28]$. Nieuwenhuijzen et al. did not find a significant survival benefit from brachytherapy, but they emphasized the functional benefits of bladder preservation therapy. Of all patients with long-term survival, 90\% preserved their own bladder [17]. Van der Steen-Banasik et al. compared 76 patients with cT1-cT2 bladder cancer treated with brachytherapy to 65 patients with cT2 bladder cancer, who would be eligible for treatment with brachytherapy, but treated with radical cystectomy. They found no difference in five and ten years disease-free survival. They concluded that for patients with solitary T1G3 or T2 bladder tumors less than $5 \mathrm{~cm}$, bladder conservative treatment with EB-BRACH is a good alternative to radical cystectomy [28].

Radical cystectomy comes with good survival, but also with significant morbidity [29-31]. In selected cases, it is suggested that patients with muscle-invasive bladder cancer can treated by partial cystectomy avoiding the morbidity of radical surgery [6,32]. Dalbagni et al. showed that $25 \%$ of patients with muscle invasive bladder cancer on transurethral resection had superficial disease or no tumor on the final pathological specimen, which favours a conservative treatment [33]. They also stated that it is important to distinguish between organ confined and non-organ confined diseases, since this is an important prognostic factor on survival. Bladder sparing treatment is most beneficial in organ confined T2 tumors, where it counterbalances the negative consequences following radical cystectomy [19]. It can be argued if the patients treated by partial cystectomy in the brachytherapy series did need radiation treatment at all. No definitive answer can be given, because of lack of randomized studies on this matter. Knoedler et al. found no difference in distant recurrence-free and cause-specific survival between radical and partial cystectomy in a matched controlled study [7]. However, reanalysis of their partial cystectomy data compared to the brachytherapy series of Koning et al. suggest an increased risk for local recurrence, which might be explained by avoidance of radiotherapy [38]. Brachytherapy can thus be complimentary to surgical TURT or partial cystectomy by treating microscopical disease and improving intravesical tumor control.

In the study of Blank et al., 8 out of 122 patients treated by brachytherapy, developed a muscle invasive tumor [39]. Of these eight patients, 3 patients $(2.5 \%)$ were treated with salvage cystectomy, and in two patients no further treatment was given because of prostate involvement. This indicates that the vast majority of the patients maintained their own bladder. Aluwini et al. reported a 10 year cystectomy-free survival of $85 \%$, in which not only cystectomy for local recurrence or severe toxicity was considered as loss of bladder function, but also persisting grade $\geq 3$ bladder toxicity [27]. Unfortunately, none of the brachytherapy articles from our systematic review report on bladder function. In the Blank et al. study late toxicity was low, with $5 \%$ of the patients having an impaired urinary function. In the majority of patients, bladder capacity $(89 \%)$ and miction frequency $(85 \%)$ improved or remained unchanged. The studies of Blank and Aluwini highlight the importance of bladder sparing techniques, and show that for selected group of patients bladder conservation for muscle-invasive bladder cancer is possible. The importance lies in the fact that patients preserve their bladder function with a normal to near-normal urinary function.

Common late effect is the development of ulceration at the implantation site. This late effect occurs in about $10 \%$ of the patients at 6 months post therapy, usually asymptomatic and self-limiting [12,14]. It is important to recognize this late effect and avoiding unnecessary biopsies. Fistula formation is very rare in $2-5 \%$ of cases $[12,13]$.

Other bladder sparing treatment modalities that include radiation therapy, consist of chemoradiation with external beam radiotherapy (without brachytherapy) [15]. Patients with tumor stage T2-T4a are included for this treatment, but - as for brachytherapy - patients with T2 tumors represent the largest group. However, patient characteristics for this treatment group are less favourable than for brachytherapy. Five and ten year overall survival rates are $52 \%$ and $35 \%$, respectively [40]. Piet et al. reported three year local control, and overall survival rates of $56 \%$ and $36 \%$, respectively for T2-T4 bladder tumors treated with external beam radiotherapy, with the majority of patients in stage T2 [37]. These results are comparable to bladder conservation treatment with brachytherapy. By brachytherapy, however, the negative effects and complications of cisplatin-based chemotherapy, such as ototoxicity and renal function impairment can be avoided [38] and, more importantly, a high dose of external beam radiotherapy to the intestine can be prevented. Chahal et al. reported a gastrointestinal complication rate of $6.6 \%$. Moreover, $2.3 \%$ of all patients needed surgical treatment for bowel strictures following radical radiotherapy [39].

\section{Conclusions}

This systematic review with meta-regression analysis shows better results after brachytherapy than after cystectomy in terms of OS, but not in CSS for patients with muscle-invasive bladder cancer. The discrepancy can be explained by the differences in tumor stage and other non-identified confounders. However, it can be concluded that brachytherapy for selected cases yields at least a similar survival as radical cystectomy for muscle-invasive bladder cancer. 


\section{Acknowledgements}

The authors thank Lukas J. Stalpers, MD, PhD for critically reviewing the manuscript

\section{Disclosure}

Authors report no conflict of interest.

\section{References}

1. Siegel R, Naishadham D, Jemal A. Cancer Statistics 2013. CA Cancer J Clin 2013; 63: 11-30.

2. Stein JP, Lieskovsky G, Cote R et al. Radical cystectomy in the treatment of invasive bladder cancer: long-term results in 1,054 patients. J Clin Oncol 2001; 19: 666-675.

3. Park J, Park S, Song $C$ et al. Effectiveness of adjuvant chemotherapy in transitional cell carcinoma of the urinary bladder with lymph node involvement and/or lymphovascular invasion treated by radical cystectomy. Urology 2007; 70: 257-262.

4. Ghoneim MA, Abdel-Latif M, el-Mekresh M et al. Radical cystectomy for carcinoma of the bladder: 2,720 consecutive cases 5 years later. J Urol 2008; 180: 121-127.

5. Henningsohn L, Steven K, Kallestrup EB et al. Distressful symptoms and well-being after radical cystectomy and orthotopic bladder substitution compared with a matched control population. J Urol 2002; 168: 168-174.

6. NCCN clinical guidelines in oncology, bladder cancer, version 1.2014; available at: http://www.nccn.org/professionals/physician_gls/pdf/bladder.pdf.

7. Knoedler JJ, Boorjian SA, Kim SP et al. Does partial cystectomy compromise oncologic outcomes for patients with bladder cancer compared to radical cystectomy? A matched case-control analysis. J Urol 2012; 188: 1115-1119.

8. Kuczyk M, Machtens S, Bokemeyer C et al. Surgical bladder preserving strategies in the treatment of muscle-invasive bladder cancer. World J Urol 2002; 20: 183-189.

9. Herr HW. Transurethral resection of muscle-invasive bladder cancer: 10-year outcome. J Clin Oncol 2001; 19: 89-93.

10. Sternberg CN, Pansadoro V, Calabrò F et al. Can patient selection for bladder preservation be based on response to chemothgerapy? Cancer 2003; 97: 1644-1652.

11. Han P, Rotman M, Schulsinger A et al. Technical basis of radiation therapy. Springer-Verlag, Heidelberg 2012; pp. 801-827.

12. Koning C, Blank L, Koedooder C et al. Brachytherapy after external beam radiotherapy and limited surgery preserves bladders for patients with solitary pT1-pT3 bladder tumors. Ann Oncol 2012; 23: 2948-2953.

13. Rozan R, Albuisson E, Donnarieix D et al. Interstitial iridium-192 for bladder cancer (a multicentric survey: 205 patients). Int J Radiat Oncol Biol Phys 1992; 24: 469-477.

14. Pernot M, Hubert J, Guillemin F et al. Combined surgery and brachytherapy in the treatment of some cancers of the bladder (partial cystectomy and interstitial iridium-192). Radiother Oncol 1996; 38: 115-120.

15. James ND, Hussain SA, Hall E et al. Radiotherapy with or without chemotherapy in muscle-invasive bladder cancer. New Engl J Med 2012; 366: 1477-1488.

16. Cheng L, Weaver a L, Leibovich BC et al. Predicting the survival of bladder carcinoma patients treated with radical cystectomy. Cancer 2000; 88: 2326-2332.

17. Nieuwenhuijzen J, Pos F, Moonen L et al. Survival after bladder-preservation with brachytherapy versus radical cystectomy; a single institution experience. Eur Urol 2005; 48: 239-245.

18. Ploeg M, Kiemeney LALM, Smits GA et al. Discrepancy between clinical staging through bimanual palpation and pathological staging after cystectomy. Urol Oncol 2012; 30: 247-251.
19. De Crevoisier R, Ammor A, Court B et al. Bladder-conserving surgery and interstitial brachytherapy for lymph node negative transitional cell carcinoma of the urinary bladder: results of a 28-year single institution experience. Radiother Oncol 2004; 72: 147-157.

20. Wijkström $H$, Norming $U$, Lagerkvist $M$ et al. Evaluation of clinical staging before cystectomy in transitional cell bladder carcinoma: a long-term follow-up of 276 consecutive patients. Br J Urol 1998; 81: 686-691.

21. Sherif A, Holmberg L, Rintala E et al. Neoadjuvant cisplatin based combination chemotherapy in patients with invasive bladder cancer: a combined analysis of two Nordic studies. Eur Urol 2004; 45: 297-303.

22. Grossman HB, Natale RB, TangenCM et al. Neoadjuvant chemotherapy plus cystectomy compared with cystectomy alone for locally advanced bladder cancer. New Engl J Med 2003; 349: 859-866.

23. Hall RR. On behalf of the International Collaboration of Trialists of the MRC Advanced Bladder Cancer Group: Updated results of a randomised controlled trial of neoadjuvant cisplatin, methotrexate and viblastine chemotherapy for muscle invasive bladder cancer. Proc Am Soc Clin 2002; 21: 178.

24. International collaboration of trialists on behalf of the MRC ABC Working Party, EORTC Genito-Urinary Group, Australian Bladder Cancer Study Group et al. Neoadjuvant cisplatin, methotrexate, and vinblastine chemotherapy for muscle-invasive bladder cancer: a randomised controlled trial. International Collaboration of Trialists. Lancet 1999; 354: 533-540.

25. Humprey PA. Urinary pathology 2004: an update. Ann Diagnostic Pathol 2004; 8: 380-389.

26. Cao D, Vollmer RT, Luly J et al. Comparison of 2004 and 1973 World Health Organization Grading Systems and their relationship to pathologic staging for predicting long-term prognosis in patients with urotelial carcinoma. Urology 2010; 76: 593-599.

27. Aluwini S, van Rooij PH, Kirkels WJ et al. Bladder function preservation with brachytherapy, external beam radiation therapy, and limited surgery in bladder cancer patients: longterm results. Int J Radiat Oncol Biol Phys 2014; 88: 611-617.

28. Van der Steen-Banasik E, Ploeg M, Witjes JA et al. Brachytherapy versus cystectomy in solitary bladder cancer: a case control, multicentre, East-Netherlands study. Radiother Oncol 2009; 93: 352-357.

29. Kaiwen L, Tianxin L, Fan X et al. Systematic reviewe and meta-analysis of comparative studies reporting early outcomes after robot-assissted radical cystectomy versus open cystectomy. Cancer Treat Rev 2013; 39: 551-560.

30. Richards KA, Steinberg GD. Perioerative outcomes in radical cystectomy: how to reduce morbidity? Curr Opin Urol 2013; 23: 456-465.

31. Stenzl A, Cowan NC, De Santis M et al. Treatment of muscle-invasive and metastatic bladder cancer: update of the EAU guidelines. Eur Urol 2011; 59: 1009-1018.

32. Gakis G, Efstathiou J, Lerner SP et al. ICUD-EAU International consultation on bladder cancer 2012: Radical cystectomy and bladder preservationfor muscle-invasive urotelhial carcinoma of the bladder. Eur Urol 2013; 63: 45-57.

33. Dalbagni G, Genega E, Hashibe M et al. Cystectomy for bladder cancer: a contemporary series. J Urol 2001; 165: 1111-1116.

34. Pieters BR, Koning CCE, Horenblas S. Re: Does Partial Cystectomy Compromise Oncologic Outcomes for Patients with Bladder Cancer Compared to Radical Cystectomy? A Matched Case-Control Analysis. JUrol 2013; 189: 1600-1601.

35. Blank LECM, Koedooder K, Van Os R et al. Results of bladder-conserving treatment, consisting of brachytherapy combined with limited surgery and external beam radiotherapy, for patients with solitary T1-T3 bladder tumors less than 5 $\mathrm{cm}$ in diameter. Int J Radiat Oncol Biol Phys 2007; 69: 454-458. 
36. Efstathiou JA, Spiegel DY, Shipley WU et al. Long-term outcomes of selective bladder preservation by combined-modality therapy for invasive bladder cancer: the MGH experience. Eur Urol 2012; 61: 705-711.

37. Piet A, Hulshof M, Pieters B et al. Clinical results of a concomitant boost radiotherapy technique for muscle-invasive bladder cancer. Strahlenther Onkol 2008; 184: 313-318.

38. Pos F, Horenblas S, Dom P et al. Organ preservation in invasive bladder cancer: brachytherapy, an alternative to cystectomy and combined modality treatment? Int J Radiat Oncol Biol Phys 2005; 61: 678-786.

39. Chahal R, Sundaram S., Iddenden R et al. A study of the morbidity, mortality and long-term survival following radical cystectomy and radical radiotherapy in the treatment of invasive bladder cancer in Yorkshire. Eur Urol 2003; 43: 246-257.

40. Pagano F, Bassi P, Tommaso PG et al. Results of contemporary radical cystectomy for invasive bladder cancer: a clinicopathological study with an emphasis on the inadequacy of the tumor, nodes and metastasis classification. J Urol 1991; 145: 45-50.

41. Quek ML, Stein JP, Clark PE et al. Natural history of surgically treated bladder carcinoma with extravesical tumor extension. Cancer 2003; 98: 955-961.

42. Madersbacher S, Hochreiter W, Burkhard F et al. Radical cystectomy for bladder cancer today. A homogeneous series without neoadjuvant therapy. J Clin Oncol 2003; 21: 690-696.

43. Jeon SH, Jeon SH, Chang SG. Clinical prognostic factors for radical cystectomy in bladder cancer. Cancer Res Treat 2005; 37: 48-53.

44. Dhar NB, Klein EA, Reuther AM et al. Outcome after radical cystectomy with limited or extended pelvic lymph node dissection. J Urol 2008; 179: 873-878.

45. Stein JP, Penson DF, Lee C et al. Long-term oncological outcomes in women undergoing radical cystectomy and orthotopic diversion for bladder cancer. J Urol 2009; 181: 2052-2058.

46. Shariat SF, Karakiewicz PI, Godoy G et al. Survivin as a prognostic marker for urothelial carcinoma of the bladder: a multicenter external validation study. Clin Cancer Res 2009; 15: 7012-7019.

47. May M, Bastian PJ, Brookman-May S et al. Pathological upstaging detected in radical cystectomy procedures is associated with a significantly worse tumour-specific survival rate for patients with clinical T1 urothelial carcinoma of the urinary bladder. Scand J Urol Nephrol 2011; 45: 251-257.

48. Hautmann RE, De Petriconi RC, Pfeiffer C et al. Radical cystectomy for urothelial carcinoma of the bladder without neoadjuvant or adjuvant therapy: long-term results in 1100 patients. Eur Urol 2012; 61: 1039-1047.

49. Neuzillet $Y$, Lebret T, Molinie V et al. Perivesical fat invasion in bladder cancer: implications for prognosis comparing pT2b, pT3a and pT3b stages and consequences for adjuvant chemotherapy indications. BJU Int 2012; 110: 1736-1741.

50. Williams GB, Trott PA, Bloom HJG. Carcinoma of the bladder treated by interstitial irradiation. Br J Urol 1981; 53: 221-224.

51. Mazeron JJ, Crook J, Chopin D et al. Conservative treatment of bladder carcinoma by partial cystectomy and interstitial iridium 192. Int J Radiat Oncol Biol Phys 1988; 15: 1323-1330.

52. Van der Werf-Messing BHP, Van Putten WLJ. Carcinoma of the urinary bladder category T2,3NxM0 treated by 40 Gy external irradiation followed by cesium 137 implant at reduced dose (50\%). Int J Radiat Oncol Biol Phys 1989; 16: 369-371. 